\title{
The Exploratory Analysis on Knowledge Creation Effective Factors in Software Requirement Development
}

\author{
Jiangping Wan ${ }^{1,2}$, Ruoting Wang ${ }^{1}$ \\ ${ }^{1}$ School of Business Administration, South China University of Technology, Guangzhou, China; ${ }^{2}$ Institute of Emerging Industrialization \\ Development, South China University of Technology, Guangzhou, China. \\ Email: scutwjp@126.com, mawangrt@gmail.com
}

Received March $16^{\text {th }}, 2010$; revised April $9^{\text {th }}, 2010$; accepted April 11 ${ }^{\text {th }}, 2010$.

\begin{abstract}
The knowledge creation effective factors were found in both necessary elements for stimulus of knowledge creation and the key influencing factors of software project success. The research was carried with the specific successful practices of Microsoft Corporation and William Johnson's analysis of $R \& D$ project knowledge creation. The knowledge creation effective factors in requirement development project are clarified through deeply interviewing the software enterprises in Guangdong province as well as other corporate information departments. The effective factors are divided with $R \& D$ project knowledge creation model in the view of organizational, team, personal and technical four levels through literature research and interview in enterprises, and the empirical study was done with questionnaire and exploratory analysis.
\end{abstract}

Keywords: Software Requirement, Knowledge Creation, Project, Organization, Empirical Study

\section{Introduction}

The smooth development of software requirements needs an efficient organization to support [1], this paper discusses the knowledge creation factors in software requirements development process in the meta-level of the software process with the instance of Microsoft corporation [2-4]. Software requirement development as a knowledge creation process, Nonaka etc. have attributed the knowledge effect factors to four reasons: intention, autonomy, creative chaos, requisite variety. On this basis, Krogh etc. re-emphasized the importance of friendly relationship to build efficient "Ba" [5]. J. P. Wan etc. analyzed from knowledge management view, some of them proposed a number of effective factors: experience in the domain, knowledge gaps, user participation, administrative support, personal capability, comprehensive training, methodology and related technology and so on $[6,7]$.

This paper is organized as follows: first knowledge creation effective factors are illustrated and the effective factors in the requirement development process are con-

This research was supported by Key Project of Guangdong Province Education Office (06JDXM63002), NSF of China (70471091), and QualiPSo (IST- FP6-IP-034763) cluded. With deeply interviewing the software enterprises in Guangdong province as well as other corporate information departments, the knowledge creation effective factors in requirement development project are clarified, finally the empirical study is done with questionnaire survey and exploratory analysis.

\section{Knowledge Creation Effective Factors}

Nonaka attributed knowledge creation effective factors to intention, self-management, creative chaos, redundancy and requisite variety [8], and re-emphasizes the friendly environment in the organization [5].

\subsection{Intention}

Nonaka indicated that the organization intention is the most important criterion in judging the authenticity of intent. If there is no organization intention, the organization will not be able to judge the value of perceived information and creative knowledge, at the same time, the organization intention must be affected by the organizational value. William Johnson considers that it should give one intention for each project at last, and it is obviously that if there is no intention, the next research will not continue [9]. Software requirements development process 
is a knowledge creation process in nature [7]. For example, the first is to establish a shared vision to enhance the team's sense of identity, belonging in the Microsoft corporation's successful rules [3].

\subsection{Self-Management}

It is that the members or the teams take actions voluntarily to improve the organization creativity. Autonomy team refers to taking the team as operation mainstay voluntarily. For example, William Johnson discovers that personal autonomy is very important for knowledge creation with interviews [9]. It allows large teams to work like small teams by dividing work into pieces, proceeding in parallel but synchronizing continuously, stabilizing in increments, and continuously finding and fixing problems in Microsoft Corporation [10].

\subsection{Creative Chaos}

Nonaka etc. illustrate that turbulence and creative chaos accelerate the interaction between the organization and environment. Members will start to question the validity of the basic attitudes. It will be opportunity to amend the fundamental thinking and insight. It is obviously that turbulence and creative chaos contribute to organizational knowledge creation [5]. William Johnson discovered that only in a few projects, turbulence and creative chaos possess function which promotes knowledge creation, just same as Nonaka's description with R \& D's research projects. In most projects, it is often closely linked with the problem's occurrence. There is no data illustrated that the creative chaos and knowledge creation have a strong correlation [9].

\subsection{Redundancy}

Redundancy usually refers to the repetition and share for group members and the unnecessary information. It is a kind of redundancy to adopt different technologies to solve the same problem during requirement development process. For example, it is an effective knowledge creation process to build a number of schemes and choose the optimal with review.

\subsection{Requisite Variety}

William Johnson concluded that all projects regard the requisite variety as a positive factor in the project knowledge creation on the R \& D project study [9]. Microsoft Corporation emphasized the small teams, which should be diversification and even in a role. There are usually many different working ways and its members should have different job skills or experience levels in a project team [5].

\subsection{Friendly Relationship}

Krogh etc. considered that the friendly relationship can remove the distrust, fear and dissatisfaction in the know- ledge creation process, and allow team members to explore new markets, new customers, new products and new manufacturing technologies in the unknown territory with enough reassurance [5].

\section{The Effective Factors in the Requirement Development Process}

The goal of software development is to exploit the high quality software which meets the customers' real requirements timely within the budget. The success of the project depends on good requirement management [11]. This paper discusses the effect factors of requirement development process in perspective of knowledge creation.

\subsection{Domain Experiences}

Cohen and Levinthal argued that if the organization had more relevant knowledge or experiences, and its absorptive capacity is better, it is a function of its past experiences accumulation [12]. Y. H. Ke etc. analyzed the importance of domain experience for system development, and discovered that the system development experience and deeply understanding of domain knowledge have a positive effect on knowledge transfer [13]. Pete Sawyer and Gerald Kotonya considered that one of the key resources in software requirement acquisition is the domain knowledge. Requirements engineers need to acquire effective knowledge on application domain. It can help them to know the tacit knowledge what stakeholders can not clearly illustrate and learn about the necessary balance between the conflict requirements [14]. For example, Microsoft's team model advocates on the basis of deeply understanding the client's business requirements and familiarly mastering related technologies to develop the project and decision-making. Therefore, the project team members should have the professional and deeply technology and business skills in themselves domains [15].

\subsection{Knowledge Gap}

It refers that the developer is lacking of business operation knowledge, knowledge of technology, and understanding of user business and software technology [16]. S. Alshawi etc. argued that it is important to have the business and technical knowledge for any enterprise [17].

\subsection{User Participation}

It is particularly important in information systems' development [18-20]. In Standish Group study, the most reason of project "disagree" factor was the lack of user participation, accounting for $13 \%$ in all failure projects. All successful projects illustrated that the most important factor was user participation, accounting for $16 \%$ of all projects [21,22]. Standish Group enumerated the top ten critical elements of software projects success with surveying 8380 software projects, the lack of user involve- 
ment is listed in the top ten reasons of software project failure $[23,24]$.

\subsection{Administrative Support}

For example, the Microsoft product development process explicitly specifies that when the projects passing the review and approval by higher managers, and the company will make sure the development progress is going smoothly, and appropriate human and resources for development will deploy through human resource department and finance department $[3,4]$.

\subsection{Personal Capability}

System analyst is a typical compound talent, and his knowledge structure not only strides the social sciences and natural sciences, but also is the perfect combination of theory and practice. For example, Microsoft asked the staff who participates the software development project have good professionalism and excellent job skills. Staff qualities include: personal quality, passion for product, concerning customer feedback, having cooperation spirit and so on [25].

\subsection{Comprehensive Training}

For example, Microsoft pays much attention to the developer's re-improved process, including learning and training and so on. The training ways are various, such as professional skills training, many kinds of seminars, training of product plan and development and so on. It also pursues to learn from the past and current research projects and products in system way [4].

\subsection{Methodology}

Today, many software organizations implement the best industry practices as the software development methodology, such as the SW-CMM (Capability Maturity Model For Software) has been promoted the Software Engineering Institute (SEI) of Carnegie Mellon University in United States since 1987 and so on [15,24].

\subsection{Related Technology}

Eriksson and Dickson argued that people share the existing knowledge and the new knowledge are created in same time, and the IT infrastructure is one of the factors impacting knowledge creation and share, including supporting information circulation, integrating tools for group problem-solving, such as Intranet, Extranet, video conferencing etc. [26].

\section{Interview in Enterprises}

We interview some experienced requirement developers, project managers, technical directors and other staffs of the software enterprises in Guangzhou P. R. China for the effect factors of software requirement development. The results are summary as follows.

\subsection{Positive Factors}

Requirement developer generally plays by the veteran in a team with abundant project experience. These skills include: 1) domain knowledge; 2) communication skill; 3) analysis \& arranging capability, comprehensive capability; 4) mastering a certain tool, specially the requirement analysis tools.

It has great importance on the methods and techniques of requirement development process in the software enterprise. First, it carries out the project generally according to the project management standards. Second, it uses prescriptive specification to develop requirement, e.g. the standard template, the standard development tool and so on. Finally, it will use variously interview methods, recording methods and tools in the requirement development process.

\subsection{Uncertain Factors}

Enterprises always hold uncertain attitude about autonomy. They considered that in the project management, whether the team processes autonomy is related to the project property. Employee must complete their work following the requirement specification and the standard format and submit the required report. However, they can complete independently in really operation.

\subsection{Negative Factors}

Software companies generally oppose chaotic environment, in particularly they do not like working in a tense environment. The creative chaos environment is not established, and tense working environment usually causes staffs turnoff.

\section{The Classification on the Effective Factors of Knowledge Creation in Software Requirement Development}

The knowledge creative factors in software requirement development are classified into three areas through the literature research and enterprise interviews (Table 1). 10 of which factors are positive, 3 are unable to determine clearly, there are two negative factors.

\section{Questionnaire Design and Collection}

The quantitative sample survey is taken to test the hypotheses of knowledge creation effective factors in software requirement development.

The questionnaire includes the following six areas: basic information, organizational characteristic, personal characteristic, technical characteristic, knowledge creation and requirement development characteristic relationship.

The first area is about the basic information, including industry type, system user, system type, the number of 
system development team, the number of system requirement development team and testee related role in order to have a more clear understanding of the sample. The second area is about organizational characteristic scale, including 4 variables and 14 items. The third area is about the team characteristic scales, including 6 variables and 16 items. The fourth area is about the personal characteristic scale, including 3 variables and 8 items. The fifth area is about the technical characteristic scales, including 2 variables and 7 items (Table 2). The sixth area is about the knowledge creation and requirement development relationship characteristic scale, including 4 items.

Table 1. Classification on the effective factors

\begin{tabular}{|c|c|c|c|}
\hline Relativity & Level & Effect factor & Remark \\
\hline \multirow{3}{*}{ Positive } & Organization & $\begin{array}{l}\text { Management support } \\
\text { Friendly environment }\end{array}$ & \multirow{5}{*}{$\begin{array}{l}\text { Literature research and } \\
\text { enterprise interviews } \\
\text { on the effective factors' } \\
\text { classification is } \\
\text { basically same. }\end{array}$} \\
\hline & Team & $\begin{array}{c}\text { Project intention } \\
\text { Requisite variety } \\
\text { User participation } \\
\text { Comprehensive training }\end{array}$ & \\
\hline & Technology & $\begin{array}{c}\text { Domain experience } \\
\text { Personal capability } \\
\text { Methodology } \\
\text { Related technology }\end{array}$ & \\
\hline Uncertain & $\begin{array}{c}\text { Organization } \\
\text { Team } \\
\text { Personal }\end{array}$ & $\begin{array}{c}\text { Redundancy } \\
\text { Self-management } \\
\text { Self-management }\end{array}$ & \\
\hline Negative & $\begin{array}{c}\text { Organization } \\
\text { Team }\end{array}$ & $\begin{array}{l}\text { Creative chaos } \\
\text { Knowledge gap }\end{array}$ & \\
\hline
\end{tabular}

Table 2. Questionnaire detailed corresponding table

\begin{tabular}{|c|c|c|c|}
\hline Level & Variable factors & Item & References \\
\hline \multirow{4}{*}{ Organization } & Management support & Area one $\mathrm{O} 1 \sim \mathrm{O} 3$ & $\begin{array}{l}\text { Nonaka (2000), Johnson (2000), Standish Group (1994), Zhang Xiang- } \\
\text { hui (2005), Chen Honggang (2003), James Emery (2002) }\end{array}$ \\
\hline & Friendly environment & Area two $\mathrm{O} 4 \sim \mathrm{O} 10$ & $\begin{array}{l}\text { Nonaka (2000), Johnson (2000), Krogh (1994), Zhang Xianghui (2005), } \\
\text { Chen Honggang (2003) }\end{array}$ \\
\hline & Creative chaos & Area two O11、O14 & Nonaka $(1995,2000)$, Johnson $(2000)$ \\
\hline & Redundancy & Area two O12、O13 & Nonaka $(1995,2000)$, Johnson $(2000)$ \\
\hline \multirow{5}{*}{ Team } & Project intention & Area three $\mathrm{T} 1 \sim \mathrm{T} 2$ & $\begin{array}{l}\text { Nonaka (1995, 2000), Johnson (2000), Zhang Xianghui (2005), Cheng } \\
\text { Honggang (2003) }\end{array}$ \\
\hline & Self-management & Area three $\mathrm{T} 3 \sim \mathrm{T} 5$ & $\begin{array}{l}\text { Nonaka (1995, 2000), Johnson (2000), Zhang Xianghui (2005), Chen } \\
\text { Honggang }(2003)\end{array}$ \\
\hline & Requisite variety & Area three $\mathrm{T} 6 \sim \mathrm{T} 7$ & Nonaka (1995, 2000), Johnson (2000), Zhang Xianghui (2005) \\
\hline & User participation & Area three $\mathrm{T} 8 \sim \mathrm{T} 10$ & $\begin{array}{l}\text { Standish Group (1994, 1995, 1999), Johnson (2000), Zhang Xianghui } \\
\text { (2005), Guinan (1998), Henri Barki (1994), Hirschheim (1994) }\end{array}$ \\
\hline & Knowledge gap & Area three $\mathrm{T} 14 \sim \mathrm{T} 16$ & Alshawi (2003), Linda (2000), Ian McBriara (2003), Gilbert (1996) \\
\hline \multirow{3}{*}{ Personal } & Self-management & Area four $\mathrm{I} 1 \sim \mathrm{I} 2$ & Nonaka (1995, 2000), Johnson (2000), Chen Honggng (2003) \\
\hline & Domain experience & Area four $\mathrm{I} 3 \sim \mathrm{I} 6$ & Cohen, Levinthal (1990), Ke Yihua (2005), Chen Honggang (2003) \\
\hline & Personal capability & Area four $\mathrm{I} 7 \sim \mathrm{I} 8$ & $\begin{array}{l}\text { Johnson (2000), Zhang Xianghui (2005), Chen Honggang (2003), Tian } \\
\text { Junguo (2003) }\end{array}$ \\
\hline \multirow[t]{2}{*}{ Technology } & Methodology & Area five $\mathrm{Te} 1 \sim \mathrm{Te} 2$ & Johnson (2000), Zhang Xianghui (2005), Chen Honggang (2003) \\
\hline & Related technology & Area five $\mathrm{Te} 3 \sim \mathrm{Te} 7$ & $\begin{array}{l}\text { Johnson (2000), Zhang Xianghui (2005), Chen Honggang (2003), Ellen } \\
\text { Gottesdiener (1999), Eriksson, Dickson (2000, 2003) }\end{array}$ \\
\hline 4 & 15 & 45 & \\
\hline
\end{tabular}




\section{The Exploratory Analysis of Requirement Development Effective Factors}

\subsection{Reclaiming Questionnaire}

Questionnaire has surveyed during December 2006 to January 2007 in Guangdong region, including Guangzhou Ferryman Management Consulting Co., Ltd., Guangdong Visionsky Information Technology Co., Ltd., Guangzhou KeenFox Engineering Co., Ltd., Computer and Technologies Solution (Shenzhen) Co., Ltd., nearly 20 enterprises, issued totally 50 e-mails, and totally recovered $26 \mathrm{~s}$, all are valid.

\subsection{Characteristic of Sample}

The highest proportion is the software industry, the number is 17 , accounting for $65.4 \%$; the rest of the industry includes financial industry, service industry and other industries accounted for $11.5 \%, 11.5 \%$ and $11.8 \%$ correspondingly.

The products which belong to interviewee's team are generally provided to the external clients to use (sample number 10 , accounting for $38.5 \%$ ), internal requirement (sample number 8, accounting for 30.8\%) and the combination of the two (sample number 8 , accounting for 30.8 $\%$ ). The products which belong to the interviewee's team, mainly MIS (sample number 17, accounting for 26.6\%) and DSS (sample number 13, accounting for 20.3\%), others such as ERP, EC, KM, special products, common products as well as other, accounting for $9.4 \%, 9.4 \%$, $6.3 \%, 10.9 \%, 1.6 \%$ and $15.6 \%$ correspondingly.

The 51 persons and above (sample number 16) is dominated, in the software development team where the interviewee is accounting for $38.5 \% ; 1$ to 10,11 to 20,21 to 50 are accounted for $26.9 \%, 23.1 \%$ and $11.5 \%$ correspondingly. The 4 to 5 persons is dominated in the requirement development team, accounting for $42.3 \%$, while, 11 persons and above, 6 to 10, and less than 3, are accounting for $26.9 \%, 19.2 \%$ and $11.5 \%$ correspondingly. The main interviewees are team project management, the sample number is 12 , accounting for $36.2 \%$; developer, requirement person, designer, tester and others are accounting for $26.9 \%, 7.7 \%, 3.8 \%$ and $7.7 \%$ correspondingly. Software industry is dominated in the interviewee's enterprises, the main products is MIS and DSS. Interviewee's software development team usually are large, the number of requirement team is 4 to 5 persons. Mainly interviewees are project managers in order to make the data more persuasive.

\subsection{Analysis on Reliability and Validity}

The Cronbach's $\alpha$ value is used to determine internal consistency because this paper is exploratory research and items are limited. The reliability of every variable is more than 0.350 after deleting items $\mathrm{I} 3$ and Te7, and reliability can be basically acceptable (Table 3).

\subsection{Statistical Analysis}

\subsubsection{Descriptive Statistics}

The descriptive statistics is illustrated in the Table $\mathbf{4}$ according to the variables in Table 2. The summary is in the following.

1) The average score of knowledge transformation \& requirement development is 4.4712 and indicates that there is close relationship between knowledge transformation and requirement development, it is same as with literature research and enterprise interview.

2) Personal capability, comprehensive training, friendly environment, project intent, customer participation, domain experience and requisite variety and etc., score more than 4 and have a higher acceptance.

3) Redundancy, creative chaos, team self-management, individual self-management, methodology and technology, score lower than 3.5 , are basically same as the expected results.

\subsubsection{One-Sample T Test}

It judges one-sample $\mathrm{T}$ test which the test value is 3.5 , confidence interval is $95 \%$. If the significant coefficient is less than 0.05 , and the upper and lower bounds are greater than 0 , indicating its value to more than 3.5 large (have passed the examination); if a significant factor greater than 0.05 , or the upper and lower bounds are less than 0 , then its value is smaller than 3.5. It is illustrated in Table 5 that the items are passed the test except redundancy, creative chaos, the team self-management, individual selfmanagement, methodology and technology.

Redundancy, creative chaos, team self-management, individual self-management, methodology and technology do not pass the test where the test value is 3.5. The reverse scoring one-sample $\mathrm{T}$ test results is illustrated in the Table 6 where the test value is 3 . Only the individual autonomy is significant, it specified that the individual autonomy plays a negative effect on knowledge creation of requirement development. The other variables do not pass the test, they are unclear type. In addition, the knowledge transfer and requirement development still passing the test where test value 4, it illustrates in Table 7 that the relationship between the requirement development and knowledge transfer is recognized highly.

\section{Conclusions}

It is illustrated in Table 8 that the management support, friendly environment, intention, requisite variety, customer participation, comprehensive training, knowledge gap, domain experience and personal capability and so on through the literature research, interview in enterprise and questionnaire survey, The nine variables have the positive effect on the knowledge creation of requirement development, where the knowledge gap is measured by reducing 
Table 3. Reliability of variables

\begin{tabular}{|c|c|c|c|c|}
\hline Variably & Item number & Cronbach's $\alpha$ value & Remove item & Reference value \\
\hline Management Support & 3 & 0.710 & & \multirow{14}{*}{0.350} \\
\hline Friendly environment & 7 & 0.771 & & \\
\hline Redundancy & 2 & 0.447 & & \\
\hline Creative chaos & 2 & 0.683 & & \\
\hline Intention & 2 & 0.410 & & \\
\hline Team self-management & 3 & 0.532 & & \\
\hline Requisite variety & 2 & 0.555 & & \\
\hline Comprehensive training & 3 & 0.824 & & \\
\hline Knowledge gap & 3 & 0.379 & & \\
\hline Personal self-management & 2 & 0.703 & \multirow{4}{*}{$\mathrm{I} 3$} & \\
\hline Domain experience & 2 & 0.552 & & \\
\hline Personal capability & 3 & 0.409 & & \\
\hline Methodology & 2 & 0.627 & & \\
\hline Technology & 4 & 0.469 & Te7 & \\
\hline
\end{tabular}

Table 4. Descriptive statistics

\begin{tabular}{|c|c|c|c|c|c|}
\hline & $\mathbf{N}$ & Minimum & Maximum & Mean & Std. Deviation \\
\hline Management support & 26 & 3.0000 & 5.0000 & 3.961538 & .5360508 \\
\hline Friendly environment & 26 & 3.4286 & 4.8571 & 4.131868 & .3426739 \\
\hline Redundancy & 26 & 2.0000 & 4.0000 & 3.096154 & .6636148 \\
\hline Creative chaos & 26 & 1.0000 & 5.0000 & 2.865385 & .9225800 \\
\hline Intention & 26 & 3.0000 & 5.0000 & 4.115385 & .4540417 \\
\hline Team self-management & 26 & 2.0000 & 4.3333 & 3.480769 & .5931590 \\
\hline Requisite variety & 26 & 3.5000 & 5.0000 & 4.019231 & .3868015 \\
\hline User participation & 26 & 3.6667 & 5.0000 & 4.423077 & .4274752 \\
\hline Comprehensive training & 26 & 3.3333 & 5.0000 & 4.192308 & .5178852 \\
\hline Knowledge gap & 26 & 3.0000 & 4.6667 & 3.987179 & .4664835 \\
\hline Personal Self-management & 26 & 1.0000 & 4.0000 & 2.500000 & .7745967 \\
\hline Experience in the field & 26 & 2.5000 & 5.0000 & 4.038462 & .5463163 \\
\hline Personal capability & 26 & 3.5000 & 5.0000 & 4.211538 & .4043038 \\
\hline Methodology & 26 & 2.5000 & 4.0000 & 3.403846 & 4902903 \\
\hline Related technology & 26 & 1.7500 & 4.0000 & 3.375000 & .4962358 \\
\hline Knowledge transfer \& requirements development & 26 & 3.7500 & 5.0000 & 4.471154 & .4707809 \\
\hline Valid N（listwise $)$ & 26 & & & & \\
\hline
\end{tabular}

Table 5. Variable one-sample $T$ test

\begin{tabular}{|c|c|c|c|c|c|c|}
\hline & \multicolumn{6}{|c|}{ Test Value $=3.5$} \\
\hline & $\mathrm{t}$ & df & Sig. (2-tailed) & Mean Difference & \multicolumn{2}{|c|}{$\begin{array}{l}\text { 95\% Confidence Interval of the } \\
\text { Difference }\end{array}$} \\
\hline Management support & 4.390 & 25 & .000 & .4615385 & .245023 & .678054 \\
\hline Friendly environment & 9.402 & 25 & .000 & .6318681 & .493459 & .770277 \\
\hline Redundancy & -3.103 & 25 & .005 & -.4038462 & -.671886 & -.135806 \\
\hline Intention & 6.911 & 25 & .000 & .6153846 & .431993 & .798776 \\
\hline Team self-management & -.165 & 25 & .870 & -.0192308 & -.258813 & .220351 \\
\hline Requisite variety & 6.845 & 25 & .000 & .5192308 & .362998 & .675463 \\
\hline User participation & 11.011 & 25 & .000 & .9230769 & .750416 & 1.095738 \\
\hline Comprehensive training & 6.816 & 25 & .000 & 6923077 & .483129 & .901486 \\
\hline Knowledge gap & 5.325 & 25 & .000 & .4871795 & .298763 & .675596 \\
\hline Personal self-management & -6.583 & 25 & .000 & -1.0000000 & -1.312866 & -.687134 \\
\hline Personal capability & 8.974 & 25 & .000 & .7115385 & .548237 & .874840 \\
\hline Methodology & -1.000 & 25 & .327 & -.0961538 & -.294186 & .101879 \\
\hline Related technology & -1.284 & 25 & .211 & -.1250000 & -.325434 & .075434 \\
\hline
\end{tabular}


Table 6. Not pass the variable reverse scoring one-sample $T$ test where the test value is 3.5

\begin{tabular}{|c|c|c|c|c|c|c|}
\hline & \multicolumn{6}{|c|}{ Test Value $=3.5$} \\
\hline & $\mathrm{t}$ & df & Sig. (2-tailed) & Mean Difference & \multicolumn{2}{|c|}{$\begin{array}{l}95 \% \text { Confidence Interval of } \\
\text { the Difference }\end{array}$} \\
\hline Redundancy (reverse) & -.739 & 25 & .467 & -.0961538 & -.364194 & .171886 \\
\hline Creative chaos (reverse) & .744 & 25 & .464 & .1346154 & -.238023 & .507254 \\
\hline Team Self-management（reverse ） & -4.133 & 25 & .000 & -.4807692 & -.720351 & -.241187 \\
\hline Methodology（reverse ） & -4.200 & 25 & .000 & -.4038462 & -.601879 & -.205814 \\
\hline Related technology（reverse ） & -3.853 & 25 & .001 & -.3750000 & -.575434 & -.174566 \\
\hline
\end{tabular}

Table 7. Knowledge transfer and requirement development one-sample $T$ test

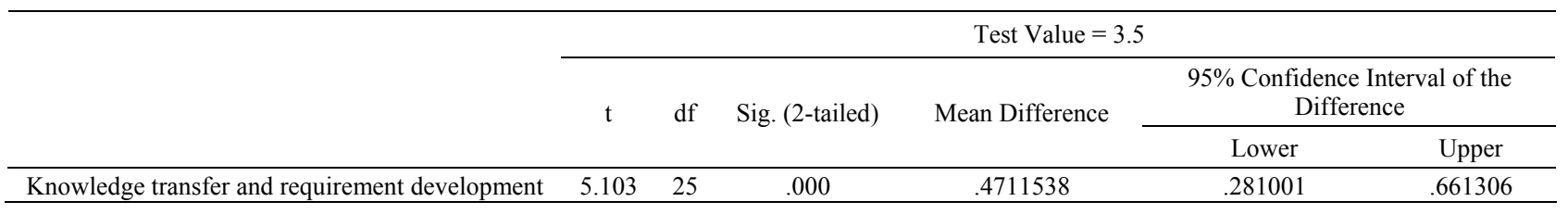

Table 8. The summarized relationship between variables

\begin{tabular}{|c|c|c|c|}
\hline Correlation & Level & Effect factor & Remark \\
\hline \multirow{9}{*}{ Positive $(+)$} & \multirow{2}{*}{ Organization } & Management support & The same as with literature research and enterprise interview \\
\hline & & Friendly environment & The same as with literature research and enterprise interview \\
\hline & \multirow{5}{*}{ Team } & Intention & The same as with literature research and enterprise interview \\
\hline & & Requisite variety & The same as with literature research and enterprise interview \\
\hline & & User participation & The same as with literature research and enterprise interview \\
\hline & & Comprehensive training & The same as with literature research and enterprise interview \\
\hline & & Knowledge gap & The same as with literature research and enterprise interview \\
\hline & \multirow{2}{*}{ Personal } & Domain experience & The same as with literature research and enterprise interview \\
\hline & & Personal capability & The same as with literature research and enterprise interview \\
\hline \multirow{4}{*}{ Uncertain (U) } & \multirow[b]{2}{*}{ Organization } & Redundancy & The same as with literature research and enterprise interview \\
\hline & & Creative chaos & $\begin{array}{l}\text { Chaos is a demon for the software business (Larry } \bullet \text { Constantine), but the creative } \\
\text { chaos has certain positive effect for enterprise management. }\end{array}$ \\
\hline & Team & Self-management & The same as with literature search and enterprise interview \\
\hline & Technology & $\begin{array}{l}\text { Methodology } \\
\text { Related technology }\end{array}$ & $\begin{array}{l}\text { Small-scale projects require little, but large-scale projects need. } \\
\text { Small-scale projects require little, but large-scale projects need. }\end{array}$ \\
\hline
\end{tabular}

knowledge gap and it is positive. Considering the literature research and interview in the enterprise, individual independency is determined negative because it illustrates significance in reverse scoring. The others, including redundancy, creative chaos, team self-management, methodology and technology, are unclear. It concludes that the technology and the methodology are support factors of project development and would be very useful for large scale projects. On the contrary, redundancy, creative chaos and team self-management should be avoided as far as possible in the project, because it is inconsistence with the goals of requirement development.

\section{Acknowledgements}

Thanks for helpful discussion with Mr. Huang Deyi, Mr.Li Jiangzhang, Mr. Chen Zhening, Mr. Wang Shuwen, Mr. Liu Bing, Brenda Huang, and Ms. Zhang Hui etc.

\section{REFERENCES}

[1] X. M. Li, L. Y. Sun and Y. L. Wang, "Research on Software Requirement Management Based on Knowledge Management," Management of Research and Development, Vol. 17, No. 2, February 2005, pp. 28-32, 39.

[2] Swebok, "Guide to Software the Software Engineering Body of Knowledge," 2004. http://www.swebok.org

[3] X. H. Zhang, "Software Development Process and Management," Tsinghua University Press, Beijing, 2005.

[4] M. A. Cusumano and R. W. Selby, "The Secrets of Microsoft," Free Press, New York, 1995.

[5] G. von Krogh, K. Ichijo and I. Nonaka, "Enabling Knowledge Creation: How to Unlock the Mystery of Tacit Knowledge and Release the Power of Innovation," Oxford University Press, New York and Oxford, 2000.

[6] J. P. Wan, Q. J. Liu, D. J. Li and H. B. Xu, "Research on Knowledge Transfer Influencing Factors in Software 
Process Improvement," Journal of Software Engineering and Applications, Vol. 3, No. 2, February 2010, pp. 134140.

[7] J. P. Wan, H. Zhang, D. Wan and D. Y. Huang, "Research on Knowledge Creation in Software Requirement Development," Journal of Software Engineering and Applications, Vol. 3, No. 5, May 2010, pp. 487-494.

[8] I. Nonaka and H. Takeuchi, "The Knowledge Creating Company," Oxford University Press, New York, 1995.

[9] W. Johnson, "Technological Innovation and Knowledge Creation: A Study of Enabling Condition and Processes of Knowledge Creation in Collaborative R \& D Project," $\mathrm{Ph} . \mathrm{D}$. Dissertation, York University, Toronto, 2000.

[10] H. G. Chen, et al., "The Science and Art of Software Development," Electronic Industry Press, Beijing, 2002.

[11] Y. S. Zhang, "The Way of System Analyzer," Electronic Industry Press, Beijing, 2006.

[12] W. M. Cohen and D. Levinthal, "Absorptive Capacity: A New Perspective on Learning and Innovation," Administrative Science Quarterly, Vol. 35, No. 1, 1990, pp. 128152.

[13] Y. H. Ke, "Research on Imparting Knowledge Transfer across Team: Based Information Systems," Master Thesis, Information Management of Institute, National Sun Yat-sen University, Taiwan, 2005.

[14] P. Sawyer and G. Kotonya, "Swebok: Software Requirements Engineering Knowledge Area Description Version 0.5," IEEE and ACM Project on Software Engineering Body of Knowledge, San Francisco, July 1999.

[15] J. P. Wan, "Research on Software Product Support Structure," Journal of Software Engineering and Applications, Vol. 2, No. 3, October 2009, pp.174-194.
[16] B. Jayatilaka, "The Role of Developer and User Knowledge Domains and Learning in Systems Development," AMCIS2000, 2000, pp.1323-1329.

[17] S. Alshawi and W. Al-Karaghouli, "Managing Knowledge in Business Requirements Identification," Logistics Information Management, Vol. 16, No. 5, 2003, pp. 341-349.

[18] H. Barki and J. Hartwick, "User Participation, Conflict and Conflict Resolution," Information Systems Research, Vol. 5, No. 2, December 1994, pp. 422-440.

[19] P. J. Guinan, J. G. Cooprider and S. Faraj, "Enabling Software Development Team Performance during Requirement Definition: A Behavioral vs. Technical Approach," Information Systems Research, July 1998, pp. 101-125.

[20] R. Hirschheim and H. K. Heinz, "Realizing Emancipatory Principles in Information Systems Development: The Case for ETHICS," Management Information Systems Quarterly, Vol. 18, No. 1, March 1994, pp. 83-109.

[21] Standish Group, "Chaos 1994," The Standish Group International, Massachusetts, 1994.

[22] Standish Group, "Chaos,” Standish Group Report, 1995.

[23] Standish Group, "Chaos: A Recipe to Success," Standish Group Report, 1999.

[24] W. S. Humphrey, "Managing the Software Process," Reading, Addison-Wesley, Massachusetts, 1989, pp. 1924.

[25] L. L. Constantine, "Beyond Chaos: The Expert Edge in Managing Software Development," Addison-Wesley, Boston, 2001.

[26] I. V. Eriksson and G. W. Dickson, "Knowledge Sharing in High Technology Company," American Conference on Information System, Vol. 36, No. 2, 2000, pp. 1330-1335. 